Portland State University

PDXScholar

\title{
Phase Considerations in the Gas/Particle Partitioning of Organic Amines in the Atmosphere
}

\author{
James F. Pankow
}

Portland State University, pankowj@pdx.edu

Follow this and additional works at: https://pdxscholar.library.pdx.edu/chem_fac

Part of the Environmental Chemistry Commons

Let us know how access to this document benefits you.

\section{Citation Details}

Pankow, J. F. (2015). Phase Considerations in the Gas/Particle Partitioning of Organic Amines in the Atmosphere. Atmospheric Environment.

This Post-Print is brought to you for free and open access. It has been accepted for inclusion in Chemistry Faculty Publications and Presentations by an authorized administrator of PDXScholar. Please contact us if we can make this document more accessible: pdxscholar@pdx.edu. 


\section{Accepted Manuscript}

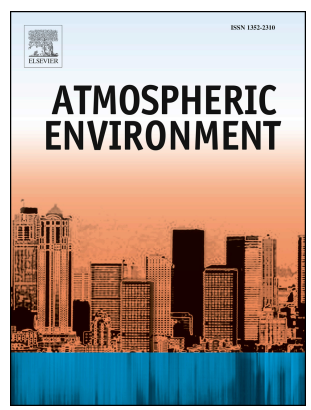

Phase Considerations in the Gas/Particle Partitioning of Organic Amines in the Atmosphere

James F. Pankow

PII: $\quad$ S1352-2310(15)30398-8

DOI: $\quad$ 10.1016/j.atmosenv.2015.09.056

Reference: $\quad$ AEA 14137

To appear in: Atmospheric Environment

Received Date: 30 December 2014

Revised Date: 21 September 2015

Accepted Date: 22 September 2015

Please cite this article as: Pankow, J.F., Phase Considerations in the Gas/Particle Partitioning of Organic Amines in the Atmosphere, Atmospheric Environment (2015), doi: 10.1016/ j.atmosenv.2015.09.056.

This is a PDF file of an unedited manuscript that has been accepted for publication. As a service to our customers we are providing this early version of the manuscript. The manuscript will undergo copyediting, typesetting, and review of the resulting proof before it is published in its final form. Please note that during the production process errors may be discovered which could affect the content, and all legal disclaimers that apply to the journal pertain. 


\section{- TECHNICAL NOTE -}

Phase Considerations in the Gas/Particle Partitioning of

Organic Amines in the Atmosphere

James F. Pankow ${ }^{1.2}$

pankowj@pdx.edu

503-725-2844 office

503-725-5950 fax 


\section{Abstract}

Amines in the atmosphere are of interest because of their likely role in new particle formation, and because of anthropogenic emissions of amines at post-combustion carbon capture (PCCC) facilities. A conceptual framework for considering the partitioning of a monobasic amine $(\mathrm{Am}=$ unprotonated "free-base form) from the gas phase to atmospheric particulate matter (PM) is presented for cases when the PM may be composed of multiple liquid phases. Three types of liquid phases are considered as being individually or simultaneously possible for absorptive uptake of atmospheric amines: w) a mostly water phase; $\alpha$ ) a mostly (by mass) organic phase that has at least some polarity (e.g., predominantly secondary organic aerosol (SOA), and may contain significant water on a mole fraction basis); and $\beta$ ) a mostly organic phase that is less polar than an $\alpha$ phase (e.g., predominantly primary organic aerosol (POA), containing little water). That one or more salts may contain the aminium ion $\mathrm{AmH}^{+}$(formed by protonation of $\mathrm{Am}$ ) is subject to the fact that the trace levels of individual amines in the atmosphere make formation of pure solid such as $\mathrm{AmHHSO}_{4(\mathrm{~s})}$ exceedingly unlikely: when solid salts of $\mathrm{AmH}^{+}$are indeed present, by far the most likely form is as a solid solution, e.g., $\left(\mathrm{NH}_{4}^{+}\right)_{1-y}\left(\mathrm{AmH}^{+}\right)_{y} \mathrm{HSO}_{4(\mathrm{~s})}^{-}$where $y \ll<1$.

Neglecting dissolution in solid salts, and considering only partitioning to liquid phases, the overall gas/particle partitioning constant is $K_{\mathrm{p}, \mathrm{tot}}\left(\mathrm{m}^{3} \mu \mathrm{g}^{-1}\right)=c_{\mathrm{p}, \mathrm{tot}} / c_{\mathrm{g}}=\sum_{\theta} f^{\theta} K_{\mathrm{p}, \mathrm{fb}}^{\theta} / \alpha_{\mathrm{fb}}^{\theta}$. The quantity $c_{\mathrm{p}, \mathrm{tot}}\left(\mu \mathrm{g} \mu \mathrm{g}^{-1}\right)$ is the total $\mathrm{Am}$ concentration $\left(\mathrm{Am}+\mathrm{AmH}^{+}\right)$in the $\mathrm{PM}$ as summed over all phases using the index $\theta(=\mathrm{w}, \alpha, \beta) ; c_{\mathrm{g}}$ is the gas phase concentration of Am; $f^{\theta}$ is the mass fraction of the total PM that is the $\theta$ phase; $K_{\mathrm{p}, \mathrm{fb}}^{\theta}$ is the gas/particle partitioning constant for the freebase (Am) form to the $\theta$ phase; and $0<\alpha_{\mathrm{fb}}^{\theta}<1$ is the fraction of the amine in the $\theta$ phase that is in the free-base form.

To date, the partitioning of amines to PM have only considered contributions to $K_{\mathrm{p}, \text { tot }}$ from absorption into a mostly water phase, according to the term $f^{\mathrm{w}} K_{\mathrm{p}, \mathrm{fb}}^{\mathrm{w}} / \alpha_{\mathrm{fb}}^{\mathrm{w}}$. However, unless the PM contains little or no organic phase material, the $\alpha$ and/or $\beta$ terms are likely to also be relevant. The Am form of a low MW amine will in general have reasonable affinities for both $\alpha$ and $\beta$ type 
69 phases, so in general $K_{\mathrm{p}, \mathrm{fb}}^{\mathrm{w}}, K_{\mathrm{p}, \mathrm{fb}}^{\alpha}$, and $K_{\mathrm{p}, \mathrm{fb}}^{\beta}$ will all be roughly similar in magnitude. And, with

70 significant water uptake into an $\alpha$ phase certain to occur at moderate to high RH values, good

71 solvation of ions will often be possible in an $\alpha$ phase. This will assist protonation of $\mathrm{Am}$ to $\mathrm{AmH}^{+}$

72 (as is known to occur for nicotine in tobacco smoke PM). The overall result is that to a first

73 approximation, $\alpha_{\mathrm{fb}}^{\mathrm{w}}$ and $\alpha_{\mathrm{fb}}^{\alpha}$ can be similar in magnitude, making $K_{\mathrm{p}, \mathrm{fb}}^{\alpha} / \alpha_{\mathrm{fb}}^{\alpha}$ likely to be generally

74 comparable to $K_{\mathrm{p}, \mathrm{fb}}^{\mathrm{w}} / \alpha_{\mathrm{fb}}^{\mathrm{w}}$. In a $\beta$ phase, ion solvation will not be as good, so that for acidic aerosol

$75 \alpha_{\mathrm{fb}}^{\beta}$ will generally be closer to one than the other two $\alpha_{\mathrm{fb}}$ values, making $K_{\mathrm{p}, \mathrm{fb}}^{\beta} / \alpha_{\mathrm{fb}}^{\beta}$ smaller than both

$76 K_{\mathrm{p}, \mathrm{fb}}^{\mathrm{w}} / \alpha_{\mathrm{fb}}^{\mathrm{w}}$ and $K_{\mathrm{p}, \mathrm{fb}}^{\alpha} / \alpha_{\mathrm{fb}}^{\alpha}$. Overall, modeling of amine behavior in the atmosphere should include

77 consideration of partitioning organic PM. Unfortunately, this will be more difficult than water-

78 phase only modeling because prediction of $\alpha_{\mathrm{fb}}$ values in multiphase PM will be greatly complicated

79 by the needs to: 1) have estimated values of acidity constants in mostly organic phases of variable

80 composition; and 2) allow distribution of chemicals over multiple liquid phases.

81

82

83

84

85

Keywords: amines, free-base, organic particulate matter, OPM, secondary organic aerosol, SOA. 


\section{$\underline{\text { (no line numbers for table) }}$}

\begin{tabular}{|c|c|}
\hline $\begin{array}{l}\text { Nomencla } \\
\text { Roman }\end{array}$ & \\
\hline $\bar{A}$ & concentration $\left(\mu \mathrm{g} \mathrm{m}^{-3}\right)$ of the amine in the gas phase (only free-base form is volatile); \\
\hline Am & free base form of an amine; \\
\hline $\mathrm{AmH}^{+}$ & monoprotonated form of an amine; \\
\hline$c_{\mathrm{p}, \mathrm{fb}}$ & concentration $\left(\mu \mathrm{g} \mathrm{g}^{-1}\right)$ of the free-base form of an amine in some liquid phase $\theta$; \\
\hline$c_{\mathrm{p}, \mathrm{tot}}$ & concentration $\left(\mu \mathrm{g} \mathrm{g}^{-1}\right)$ of total (free-base + protonated) amine in some liquid phase $\theta$; \\
\hline$c_{\mathrm{g}}$ & concentration $\left(\mu \mathrm{g} \mathrm{m}^{-3}\right)$ of the amine in the gas phase (only free-base form is volatile); \\
\hline$f^{\theta}$ & weight fraction of the PM that is the absorbing liquid phase $\theta$ \\
\hline$F_{\mathrm{fb}}$ & $\begin{array}{l}\text { particle-phase associated concentration }\left(\mu \mathrm{g} \mathrm{m}^{-3}\right) \text { of the free-base form of an amine in some } \\
\text { liquid phase } \theta \text {; }\end{array}$ \\
\hline$F_{\text {tot }}$ & $\begin{array}{l}\text { particle-phase associated concentration }\left(\mu \mathrm{g} \mathrm{m}^{-3}\right) \text { of the total (free-base+protonated) amine in } \\
\text { some liquid phase } \theta \text {; }\end{array}$ \\
\hline$K_{\mathrm{a}}$ & $\begin{array}{l}\text { acidity constant on molal scale, using solution phase activities; referenced to infinite dilution in } \\
\text { water; }\end{array}$ \\
\hline${ }^{\mathrm{c}} K_{\mathrm{a}}$ & $\begin{array}{l}\text { acidity constant on molal scale, using solution phase concentrations; value depends on the } \\
\text { composition of the medium; }\end{array}$ \\
\hline$K_{\mathrm{H}, \mathrm{fb}}^{\mathrm{w}}$ & $\begin{array}{l}\text { Henry's gas law constant }\left(m \text { atm }^{-1}\right) \text { for partitioning to a mostly phase, with molal activity for } \\
\text { the dissolved species; referenced to infinite dilution in water; }\end{array}$ \\
\hline${ }^{\mathrm{c}} K_{\mathrm{H}, \mathrm{fb}}^{\mathrm{w}}$ & $\begin{array}{l}\text { Henry's gas law partitioning constant }\left(m \mathrm{~atm}^{-1}\right) \text { with molal concentration for the dissolved } \\
\text { species; value depends on the composition of the medium; }\end{array}$ \\
\hline$K_{\mathrm{p}, \mathrm{fb}}$ & $\begin{array}{l}\text { gas/particle partitioning constant }\left(\mathrm{m}^{3} \mu \mathrm{g}^{-1}\right) \text { for the free-base form of an amine to some liquid } \\
\text { phase } \theta \text {; }\end{array}$ \\
\hline$K_{\mathrm{p}, \text { tot }}$ & $\begin{array}{l}\text { gas/particle partitioning constant }\left(\mathrm{m}^{3} \mu \mathrm{g}^{-1}\right) \text { for total (free-base }+ \text { protonated) amine to some } \\
\text { liquid phase } \theta\end{array}$ \\
\hline$M^{\theta}$ & mass concentration $\left(\mu \mathrm{g} \mathrm{m}^{-3}\right)$ of absorbing liquid phase $\theta$ \\
\hline$M_{\text {tot }}$ & total mass concentration $\left(\mu \mathrm{g} \mathrm{m}^{-3}\right)$ of $\mathrm{PM}$ \\
\hline$\overline{\mathrm{MW}}$ & mean molecular weight $\left(\mathrm{g} \mathrm{mol}^{-1}\right)$ of an absorbing liquid PM phase $\theta$ \\
\hline$\overline{\mathrm{MW}}^{\mathrm{w}}$ & mean molecular weight $\left(\mathrm{g} \mathrm{mol}^{-1}\right)$ of an absorbing, mostly water liquid PM phase; \\
\hline MW & molecular weight $\left(\mathrm{g} \mathrm{mol}^{-1}\right)$ \\
\hline OPM & organic particulate matter; \\
\hline$p$ & gas-phase pressure (atm); \\
\hline$p_{\mathrm{L}, \mathrm{Am}}^{\mathrm{o}}$ & vapor-pressure (atm) at temperature $T$ of pure liquid amine (sub-cooled if necessary); \\
\hline $\mathrm{pH}_{\mathrm{eff}}$ & the $\mathrm{pH}$ that in dilute water that would give the same $\alpha_{\mathrm{fb}}$ as in liquid phase $\theta$; \\
\hline $\mathrm{PM}$ & particulate matter $\left(\mu \mathrm{g} \mathrm{m}^{-3}\right)$ \\
\hline$R$ & gas constant $\left(8.2 \times 10^{-5} \mathrm{~m}^{3}\right.$ atm mol $\left.{ }^{-1} \mathrm{~K}^{-1}\right)$; \\
\hline SOA & secondary organic aerosol; \\
\hline$T$ & temperature $(\mathrm{K})$ \\
\hline$x$ & mole-fraction-scale concentration of compound in the liquid phase $\theta$; \\
\hline Greek & \\
\hline$\alpha$ & phase $\alpha$ - e.g., a mostly SOA phase: a phase that is mostly organic by mass, is at least \\
\hline
\end{tabular}


somewhat polar, and is more polar than a $\beta$ phase;

$\alpha_{\mathrm{fb}} \quad$ fraction of amine in the free-base form in liquid phase $\theta$;

$\beta \quad$ phase $\beta$ - e.g., a mostly hydrophobic POA phase: a phase that is mostly organic by mass, and is less polar than an $\alpha$ phase;

$\gamma \quad$ molal scale activity coefficient (dimensionless) of a compound in liquid phase $\theta$;

mole-fraction-scale activity coefficient (dimensionless) of a compound in liquid phase $\theta$.

86 


\section{Introduction}

The behavior of amines in the atmosphere is of increasing interest. The nucleation of new particles in the ambient atmosphere has been discussed as involving molecular-scale clusters that include natural amines (Barsanti et al., 2009; Smith et al., 2010; Bzdek et al., 2011a,b; Yli-Juuti et al., 2013; Bzdek et al., 2014). Amines such as monoethanol amine (MEA) (Rochelle, 2009), diethanol amine (DEA), and methyldiethanolamine (MDEA) (Reynolds et al., 2012) are being considered for use in post-combustion carbon capture (PCCC) of $\mathrm{CO}_{2}$ at fossil fuel energy plants. Measurements of amines in the ambient environment continue to be the focus of recent study (e.g., Zheng et al., 2015).

The unprotonated, "free-base" form of an amine is represented herein as Am, which is assumed to be monobasic; protonated $\mathrm{Am}$ is represented $\mathrm{AmH}^{+}$. By analogy with ammonia, which forms solid salts of $\mathrm{NH}_{4}^{+}$such as $\mathrm{NH}_{4} \mathrm{HSO}_{4(\mathrm{~s})}$ and is enormously soluble in water, Ge et al. (2011) discuss that: 1) solid salts of $\mathrm{AmH}^{+}$may form in the atmosphere with bisulfate (e.g., as $\mathrm{AmH}^{+} \mathrm{HSO}_{4(\mathrm{~s})}^{-}$), sulfate, or nitrate; and 2) strong partitioning of low-MW amines can occur into a particle phase that is largely water (by mass), especially under low-pH conditions so that the reaction $\mathrm{Am}+\mathrm{H}^{+} \rightarrow \mathrm{AmH}^{+}$can occur. However, as regards formation of salts, trace levels of $\mathrm{AmH}^{+}$will not be present as pure solid salt(s). Rather, since ionic solid solutions are very well known, including solid solutions involving salts of ammonium and sulfate (e.g., Smith, 1992), it is certain that when present in ionic solids aminium ions will be present as dilute ionic solid solution(s). Evidence for such formation can be found in the study by Chan and Chan (2013) wherein reactions of ammonia gas with solid ammonium salts were considered.

With ammonium bisulfate, the result would be $\left(\mathrm{NH}_{4}^{+}\right)_{1-y}\left(\mathrm{AmH}^{+}\right)_{y} \mathrm{HSO}_{4(\mathrm{~s})}^{-}$where $y<<1$. Second, as regards absorptive partitioning, in addition to uptake into a mostly aqueous particulate matter (PM), 
111 in the general case it will also be necessary to consider absorption into mostly organic particulate

112 matter (OPM), especially when there is appreciable water in the OPM. Guo et al. (2014) used

113 indirect aerosol measurements to estimate that significant levels of water were present within OPM

114 at ground-level in the southeast United States during May to November, 2012. Those results are

115 supported by "molecular view" (MV) chemical transport modeling of water uptake into OPM in

116 that region by Pankow et al. (2015) and Jathar et al. (2015). The results of Guo et al. (2014),

117 Pankow et al. (2015), and Jathar et al. (2015) all support the view that in the southeast United

118 States, particle water within SOA OPM can currently reach a third or more of the total water+OPM

119 mass loading. If the MW of the organic portion is $\sim 200 \mathrm{~g} \mathrm{~mol}^{-1}$, with the $\mathrm{MW}$ of water only $18 \mathrm{~g}$

$120 \mathrm{~mol}^{-1}$, then $1 / 3$ by mass water corresponds to mole fraction values of $x_{\mathrm{w}}=0.85$ and $x_{\mathrm{o}}=0.15$. If it is

121 assumed that the condensed SOA OPM resembles an aliphatic $\mathrm{C}_{10}$ diacid $(\mathrm{MW}=202)$, for dilute

122 MEA and DEA in a solution within $x_{\mathrm{w}} \approx 0.85$ and $x_{\mathrm{0}} \approx 0.15$, the UNIFAC algorithm for mole-

123 fraction scale activity coefficients (Fredunslund et al., 1977) predicts the Am-form activity

124 coefficients are $\zeta_{\mathrm{MEA}}=0.33$ and $\zeta_{\mathrm{DEA}}=0.20$. For a mostly water phase with $\left(x_{\mathrm{w}} \approx 1\right)$, the predicted

125 values are $\zeta_{\mathrm{MEA}}=0.37$ and $\zeta_{\mathrm{DEA}}=0.55$, so that an OPM phase containing appreciable water can be

126 expected to be at least as favored for uptake of low MW amines as $x_{\mathrm{w}} \approx 1$. Moreover, water in

127 OPM can solvate $\mathrm{AmH}^{+}$ions: when aerosol acidity increases, uptake of an amine will increase not

128 only in particle water but also in the OPM. (It is well-known that tobacco smoke OPM is usually

129 sufficiently acidic to greatly increase the partitioning of nicotine from the gas phase (Liang and

130 Pankow, 1996; Pankow et al., 1997; Pankow, 2001)). Further, when a mostly water $\left(x_{\mathrm{w}} \approx 1\right)$ phase

131 contains high concentrations of dissolved salts, "salting-out" effects can reduced the comfort level

132 of the Am in the salty-water phase relative to an organic-rich phase (Zuend and Seinfeld, 2012).

133 2. Equations

134 2.1. Effects of Protonation of Amines in Absorptive Partitioning 
135

136

137

138

142

In the gas phase, the neutral "free-base" Am is the only form present: AmH+ is essentially completely non-volatile. Within a given condensed liquid PM phase, only a fraction of the total amine in the phase is ever in the $\mathrm{Am}$ form: $\mathrm{AmH}^{+}$is always present to some extent. $\mathrm{Am}$ and $\mathrm{AmH}^{+}$are conjugate opposites:

$$
\underset{\mathrm{AmH}^{+}}{\mathrm{AmH}^{+} \text {as acid }} \rightarrow \underset{\leftarrow \text { Am as base }}{\mathrm{Am}}+\mathrm{H}^{+}
$$

In a condensed solution phase, the acidity constant for $\mathrm{AmH}^{+}$is

$$
K_{\mathrm{a}}=\frac{\{\mathrm{Am}\}\left\{\mathrm{H}^{+}\right\}}{\left\{\mathrm{AmH}^{+}\right\}}=\frac{\gamma_{\mathrm{Am}}[\mathrm{Am}] \gamma_{\mathrm{H}^{+}}\left[\mathrm{H}^{+}\right]}{\gamma_{\mathrm{AmH}^{+}}\left[\mathrm{AmH}^{+}\right]}
$$

The concentration scale for both the terms in braces and brackets is the molal scale, so the $\gamma$ values are molal-scale activity coefficients. $K_{\mathrm{a}}$ values are most commonly tabulated for the condition of "infinitely dilute" water in which $\gamma_{\mathrm{Am}}=\gamma_{\mathrm{H}^{+}}=\gamma_{\mathrm{AmH}^{+}} \equiv 1$.

For a given constant composition of the liquid phase in which the equilibrium is being attained, as usual $\mathrm{p} K_{\mathrm{a}} \equiv-\log K_{\mathrm{a}}$, and $\mathrm{p}^{\mathrm{c}} K_{\mathrm{a}} \equiv-\log { }^{\mathrm{c}} K_{\mathrm{a}}$ with

$$
{ }^{c} K_{\mathrm{a}} \equiv \frac{[\mathrm{Am}]\left[\mathrm{H}^{+}\right]}{\left[\mathrm{AmH}^{+}\right]}=K_{\mathrm{a}} \frac{\gamma_{\mathrm{AmH}^{+}}}{\gamma_{\mathrm{Am}_{\mathrm{H}}} \gamma_{\mathrm{H}^{+}}}
$$

The $\gamma$ values depend on the composition of the medium, so that ${ }^{c} K_{\mathrm{a}}$ values for a given acid can be very different in different media. For example, the group $\gamma_{\mathrm{AmH}^{+}} /\left(\gamma_{\mathrm{Am}^{\prime}} \gamma_{\mathrm{H}^{+}}\right)$will be very different in dilute water $v s$. in a phase in which $x_{\mathrm{w}}=0.25$ and some $x_{\mathrm{o}}=0.75$. In fact, for two different acids (including $\mathrm{AmH}^{+}$ions), it can easily be the case that the $\mathrm{p}^{\mathrm{c}} K_{\mathrm{a}}$ order is reversed between one phase vs. another.

The fraction of the free base in a liquid phase is denoted $\alpha_{\mathrm{fb}}$ (Liang and Pankow, 1996), with $0 \leq \alpha_{\mathrm{fb}} \leq 1$. When is mono-basic, then within the phase the fraction of $\mathrm{AmH}^{+}$is $1-\alpha_{\mathrm{fb}}$ and 


$$
\alpha_{\mathrm{fb}} \equiv \frac{[\mathrm{Am}]}{[\mathrm{Am}]+\left[\mathrm{AmH}^{+}\right]} \quad 1-\alpha_{\mathrm{fb}}=\frac{\left[\mathrm{AmH}^{+}\right]}{[\mathrm{Am}]+\left[\mathrm{AmH}^{+}\right]}
$$

For absorptive partitioning to a given liquid phase (Liang and Pankow, 1996; Pankow et al., 2003)

$$
K_{\mathrm{p}, \mathrm{fb}}\left(\mathrm{m}^{3} \mu \mathrm{g}^{-1}\right)=\frac{c_{\mathrm{p}, \mathrm{fb}}}{c_{\mathrm{g}}}=\frac{c_{\mathrm{p}, \mathrm{fb}}}{A}
$$

where $c_{\mathrm{p}, \mathrm{fb}}\left(\mu \mathrm{g} \mu \mathrm{g}^{-1}\right)$ is the PM-phase concentration of the Am portion, and $c_{\mathrm{g}}\left(\mu \mathrm{g} \mathrm{m}^{-3}\right) \equiv A\left(\mu \mathrm{g} \mathrm{m}^{-3}\right)$ is concentration of Am in the gas-phase. The counterpart to $A$ is $F\left(\mu \mathrm{g} \mathrm{m}^{-3}\right)$, which is the PMassociated concentration for the aerosol system.

As with the uptake of ammonia into particle water, Eq.(5) is an incomplete treatment of Am partitioning into $\mathrm{PM}$ because increasing $\left\{\mathrm{H}^{+}\right\}$in a liquid PM phase (i.e., decreasing the $\mathrm{pH}$ conditions) will decrease $\alpha_{\mathrm{fb}}$. Since it is Am that is in direct gas/particle exchange with the gas phase, more total Am can be present in the PM at low pH than at high pH (Pankow et al., 1997; 2003; Ge et al., 2011).

It is common in the atmosphere that the PM contains more than one absorptive liquid phase. You et al. (2014) discuss liquid-liquid phase separation in systems involving laboratory produced secondary organic material and aqueous salt solution, and Zuend and Seinfeld (2012) discuss predictions of phase separation in such systems. Erdakos and Pankow (2004) discuss cases when relatively polar SOA compounds and non-polar primary organic aerosol (POA) compounds are jointly present at similar mass concentrations with some water. The cases considered resulted in phase separation into two mostly organic phases, one phase $(\alpha)$ being more polar and containing more water than the other $(\beta)$. Since a mostly aqueous phase is possible (You et al., 2014; Zuend and Seinfeld, 2012), it can be concluded that atmospheric PM with three liquid phases is possible. The mass concentration of the $\theta$ phase portion of the PM is denoted $M^{\theta}\left(\mu \mathrm{g} \mathrm{m}^{-3}\right)$

$$
c_{\mathrm{p}, \mathrm{fb}}^{\theta}\left(\mu \mathrm{g} \mu \mathrm{g}^{-1}\right) \equiv \frac{F_{\mathrm{fb}}^{\theta}}{M^{\theta}} \quad c_{\mathrm{p}, \mathrm{tot}}^{\theta}\left(\mu \mathrm{g} \mu \mathrm{g}^{-1}\right) \equiv \frac{F_{\mathrm{tot}}^{\theta}}{M^{\theta}}
$$




$$
K_{\mathrm{p}, \mathrm{fb}}^{\theta}\left(\mathrm{m}^{3} \mu \mathrm{g}^{-1}\right)=\frac{F_{\mathrm{fb}}^{\theta} / M^{\theta}}{c_{\mathrm{g}}}=\frac{F_{\mathrm{fb}}^{\theta} / M^{\theta}}{A} \quad K_{\mathrm{p}, \mathrm{tot}}^{\theta}\left(\mathrm{m}^{3} \mu \mathrm{g}^{-1}\right)=\frac{F_{\mathrm{tot}}^{\theta} / M^{\theta}}{c_{\mathrm{g}}}=\frac{F_{\mathrm{tot}}^{\theta} / M^{\theta}}{A}
$$

178

179 where $c_{\mathrm{p}, \mathrm{tot}}^{\theta}\left(\mu \mathrm{g} \mu \mathrm{g}^{-1}\right) \equiv F_{\text {tot }}^{\theta} / M^{\theta}$ is the total (i.e., $\left.\mathrm{Am}+\mathrm{AmH}^{+}\right) \theta$-phase mass concentration of the amine (computed as Am). With $\alpha_{\mathrm{fb}}^{\theta}$ defined for each phase $\theta$ according to Eq.(4), then

$$
\begin{gathered}
c_{\mathrm{p}, \mathrm{fb}}^{\theta}=\alpha_{\mathrm{fb}}^{\theta} c_{\mathrm{p}, \mathrm{tot}}^{\theta} \\
F_{\mathrm{fb}}^{\theta}=\alpha_{\mathrm{fb}}^{\theta} F_{\mathrm{tot}}^{\theta} \\
K_{\mathrm{p}, \mathrm{fb}}^{\theta}\left(\mathrm{m}^{3} \mu \mathrm{g}^{-1}\right)=\frac{\alpha_{\mathrm{fb}}^{\theta} c_{\mathrm{p}, \mathrm{tot}}^{\theta}}{c_{\mathrm{g}}}=\frac{\alpha_{\mathrm{fb}}^{\theta} F_{\mathrm{tot}}^{\theta} / M_{\theta}}{c_{\mathrm{g}}} \\
\frac{F_{\mathrm{tot}}^{\theta} / M_{\theta}}{c_{\mathrm{g}}}=\frac{c_{\mathrm{p}, \mathrm{tot}}^{\theta}}{c_{\mathrm{g}}}=\frac{K_{\mathrm{p}, \mathrm{fb}}^{\theta}}{\alpha_{\mathrm{fb}}^{\theta}} \\
K_{\mathrm{p}, \mathrm{tot}}^{\theta}=\frac{K_{\mathrm{p}, \mathrm{bb}}^{\theta}}{\alpha_{\mathrm{fb}}^{\theta}}
\end{gathered}
$$

Partitioning of an amine to a phase $\theta$ is greatly enhanced when the phase is acidic because then $\alpha_{\mathrm{fb}}^{\theta}$ $<<1$, and $K_{\mathrm{p}, \mathrm{tot}}^{\theta}>K_{\mathrm{p}, \mathrm{fb}}^{\theta}($ Pankow et al. 1997).

$K_{\mathrm{p}, \mathrm{fb}}^{\theta}$ for an amine in the $\theta$ phase depends on: a) the liquid vapor pressure $p_{\mathrm{L}}^{\mathrm{o}}(T)$ of the amine; and b) how its structural characteristics compare to those comprising the major components of the $\theta$ phase (and thus set the value of $\zeta_{\mathrm{Am}}^{\theta}$ ). The value of $\alpha_{\mathrm{fb}}^{\theta}$ and thus the overall partitioning constant $K_{\mathrm{p}, \mathrm{tot}}^{\theta}$ depend on: a) the basicity of the amine in the $\theta$ phase; and b) the effective $\mathrm{pH}$ conditions in the $\theta$ phase. Different liquids always exhibit different equilibrium solvation properties, so that when comparing phases in a multi-phase PM, no two $K_{\mathrm{p}, \mathrm{fb}}^{\theta}$ and no two $\alpha_{\mathrm{fb}}^{\theta}$ values will ever be exactly equal.

Summing over all phases, the total mass concentration in the PM is 


$$
\begin{aligned}
F_{\mathrm{tot}}=\sum_{\theta} F_{\mathrm{tot}}^{\theta} & =\sum_{\theta} c_{\mathrm{p}, \mathrm{tot}}^{\theta} M^{\theta} \\
& =\sum_{\theta} c_{\mathrm{p}, \mathrm{fb}}^{\theta} M^{\theta} / \alpha_{\mathrm{fb}}^{\theta}=\sum_{\theta} A K_{\mathrm{p}, \mathrm{fb}}^{\theta} M^{\theta} / \alpha_{\mathrm{fb}}^{\theta}
\end{aligned}
$$

$197 f^{\theta}$ gives the mass fraction of the total PM that is the $\theta$ phase:

198

$$
M^{\theta}=f^{\theta} M_{\mathrm{tot}}
$$

199

The overall $K_{\mathrm{p}}$ for total amine in the PM is

$$
K_{\mathrm{p}, \mathrm{tot}}=\frac{F_{\mathrm{tot}} / M_{\mathrm{tot}}}{A}=\sum_{\theta} f^{\theta} K_{\mathrm{p}, \mathrm{fb}}^{\theta} / \alpha_{\mathrm{fb}}^{\theta}
$$

By analogy with the case for a non-ionizing compound, for the aerosol system the fraction of the total amine (free-base + protonated) in the PM phase is given by (Liang and Pankow, 1996)

$$
f_{\mathrm{p}}=\frac{F_{\mathrm{tot}}}{F_{\mathrm{tot}}+A}
$$

From Eq.(16), $F_{\text {tot }} / A=K_{\mathrm{p}, \mathrm{tot}} M_{\mathrm{tot}}$,

$$
f_{\mathrm{p}}=\frac{K_{\mathrm{p}, \mathrm{tot}} M_{\mathrm{tot}}}{K_{\mathrm{p}, \mathrm{tot}} M_{\mathrm{tot}}+1}=\frac{M_{\mathrm{tot}} \sum_{\theta} f^{\theta} K_{\mathrm{p}, \mathrm{fb}}^{\theta} / \alpha_{\mathrm{fb}}^{\theta}}{M_{\text {tot }} \sum_{\theta} f^{\theta} K_{\mathrm{p}, \mathrm{fb}}^{\theta} / \alpha_{\mathrm{fb}}^{\theta}+1}
$$

The value of $f_{\mathrm{p}}$ increases towards 1 with: increasing $M_{\mathrm{tot}}$ each increasing $K_{\mathrm{p}, \mathrm{fb}}^{\theta}$; and each decreasing $\alpha_{\mathrm{p}, \mathrm{fb}}^{\theta}$. Increasingly acidic conditions will generally cause all $\alpha_{\mathrm{fb}}^{\theta}$ to decrease, and vice versa. If in addition to absorptive partitioning some precipitation as a salt occurs, then the expression for $f_{\mathrm{p}}$ will be more complicated than Eq.(18).

\subsection{Partitioning to a Particular Phase}

$$
K_{\mathrm{p}, \mathrm{fb}}^{\theta}=\frac{c_{\mathrm{p}, \mathrm{fb}}^{\theta}\left(\mu \mathrm{g} \mu \mathrm{g}^{-1}\right)}{c_{\mathrm{g}}\left(\mu \mathrm{g} \mathrm{m}^{-3}\right)}=\frac{R T}{10^{6} \overline{\mathrm{MW}}^{\theta} \zeta_{\mathrm{Am}}^{\theta} p_{\mathrm{L}, \mathrm{Am}}^{\mathrm{o}}}
$$

213 where $R$ is the gas constant $\left(=8.2 \times 10^{-5} \mathrm{~m}^{3}\right.$ atm mol$\left.{ }^{-1} \mathrm{~K}^{-1}\right) ; T(\mathrm{~K})$ is temperature; $\overline{\mathrm{MW}}^{\theta}\left(\mathrm{g} \mathrm{mol}^{-1}\right)$ is 
214 the mean molecular weight of the $\theta$ phase; $\zeta_{\mathrm{Am}}^{\theta}$ is the mole-fraction scale activity coefficient of Am

215 in the $\theta$ phase; and $p_{\mathrm{L}, \mathrm{Am}}^{\mathrm{o}}(\mathrm{atm})$ is the vapor-pressure at temperature $T$ of pure Am as a liquid (sub-

216 cooled if necessary). Equilibrium partitioning of a gaseous $\mathrm{fb}$ amine to a w phase is often

217 parameterized in terms of the activity-based Henry's Law constant $K_{\mathrm{H}}$ for water

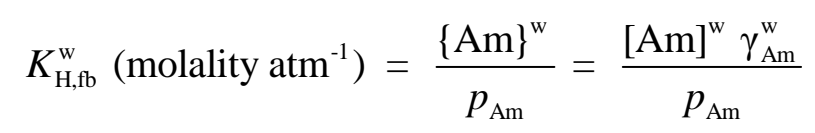

219 where we add the subscript fb for clarity, and $p(\mathrm{~atm})$ is the gas-phase pressure. In dilute water,

$220 \gamma_{\mathrm{Am}}^{\mathrm{w}}=1 . K_{\mathrm{p}, \mathrm{fb}}^{\mathrm{w}}\left(\mu \mathrm{g} \mu \mathrm{g}^{-1}\right.$ per $\left.\mu \mathrm{g} \mathrm{m}^{-3}\right)$ is an activity-based partitioning constant. The corresponding

221 concentration-based partitioning constant is

$$
{ }^{\mathrm{c}} K_{\mathrm{H}, \mathrm{fb}}^{\mathrm{w}} \equiv \frac{[\mathrm{Am}]^{\mathrm{w}}}{p_{\mathrm{Am}}}=\frac{K_{\mathrm{H}, \mathrm{fb}}^{\mathrm{w}}}{\gamma_{\mathrm{Am}}^{\mathrm{w}}}
$$

${ }^{\mathrm{c}} K_{\mathrm{H}, \mathrm{fb}}^{\mathrm{w}}$ and $K_{\mathrm{p}, \mathrm{fb}}^{\mathrm{w}}$ are both gas/water partition coefficients that use concentration in the w phase. By

means of the Ideal Gas Law and unit conversions,

$$
K_{\mathrm{p}, \mathrm{fb}}^{\mathrm{w}}=\frac{{ }^{\mathrm{c}} K_{\mathrm{H}, \mathrm{fb}}^{\mathrm{w}}\left(\frac{\mathrm{mol}}{\mathrm{kg}-\mathrm{atm}}\right) R T\left(\frac{\mathrm{m}^{3}-\mathrm{atm}}{\mathrm{mol}-\mathrm{K}} \mathrm{K}\right)}{10^{9}\left(\frac{\mu \mathrm{g}}{\mathrm{kg}}\right)}=\frac{\frac{K_{\mathrm{H}, \mathrm{fb}}^{\mathrm{w}}}{\gamma_{\mathrm{Am}}^{\mathrm{w}}} R T}{10^{9}}
$$

\section{3. $\mathrm{pH}_{\text {eff }}$ Values in Multi-Phase PM}

A schematic representation of amine partitioning is provided in Figure 1, which assumes the presence of three liquid phase types and one solid salt phase. Table 1 summarizes other possible combinations. "Liquid" refers to any phase that, regardless of viscosity, is characterizable 


$$
\alpha_{\mathrm{fb}}^{\mathrm{w}}=\frac{[\mathrm{Am}]^{\mathrm{w}}}{[\mathrm{Am}]^{\mathrm{w}}+\left[\mathrm{AmH}^{+}\right]^{\mathrm{w}}}=\frac{1}{1+\left[\mathrm{AmH}^{+}\right]^{\mathrm{w}} /[\mathrm{Am}]^{\mathrm{w}}}
$$

233 In dilute water, all $\gamma=1$ and $\mathrm{pH}^{\mathrm{w}}=-\log \left[\mathrm{H}^{+}\right]$, and Eqs.(2) and (19) give

$$
\alpha_{\mathrm{fb}}^{\mathrm{w}}=\frac{1}{1+\frac{\left[\mathrm{H}^{+}\right]^{\mathrm{w}}}{K_{\mathrm{a}}}}=\frac{1}{1+\frac{10^{-\mathrm{pH}}}{10^{-\mathrm{p} K_{\mathrm{a}}}}}=\frac{10^{-\mathrm{p} K_{\mathrm{a}}}}{10^{-\mathrm{p} K_{\mathrm{a}}}+10^{-\mathrm{pH}^{\mathrm{w}}}}
$$

Eq.(24) relates three quantities for dilute water: 1) $\left.\alpha_{\mathrm{fb}} ; 2\right)$ the basicity of the amine $\left(\mathrm{p} K_{\mathrm{a}}\right)$; and 3) the basicity of the solution $(\mathrm{pH})$.

(Pankow, 2001):

$$
\mathrm{pH}_{\mathrm{eff}}^{\theta} \equiv-\log \frac{\gamma_{\mathrm{Am}}^{\theta}\left[\mathrm{H}^{+}\right] \gamma_{\mathrm{H}^{+}}^{\theta}}{\gamma_{\mathrm{AmH}^{+}}^{\theta}}
$$

241 (For dilute water, $\mathrm{pH}_{\mathrm{eff}}^{\theta}=\mathrm{pH}$.) By Eq.(2),

$$
\begin{aligned}
\frac{\left[\mathrm{AmH}^{+}\right]^{\theta}}{[\mathrm{Am}]^{\theta}} & =\frac{1}{K_{\mathrm{a}}} \frac{\gamma_{\mathrm{Am}}^{\theta}\left[\mathrm{H}^{+}\right]^{\theta} \gamma_{\mathrm{H}^{+}}^{\theta}}{\gamma_{\mathrm{AmH}^{+}}^{\theta}} \\
& =\frac{1}{10^{-\mathrm{p} K_{\mathrm{a}}}} 10^{-\mathrm{pH}_{\mathrm{eff}}^{\theta}}
\end{aligned}
$$

244 Thus, even when we do not know any of the relevant $\gamma$ values, we can still always write for any

245 particular amine in any liquid phase that

$$
\alpha_{\mathrm{fb}}^{\theta}=\frac{10^{-\mathrm{p} K_{\mathrm{a}}}}{10^{-\mathrm{p} K_{\mathrm{a}}}+10^{-\mathrm{pH}} \mathrm{H}_{\mathrm{eff}}^{\theta}}
$$

247 For monoethanol amine, $\mathrm{p} K_{\mathrm{a}}=8.06$ at $20{ }^{\circ} \mathrm{C}$ (Gonzalez et al., 1980). Thus, if at $25{ }^{\circ} \mathrm{C}$ the value of $248 \alpha_{\mathrm{fb}}^{\theta}$ in the $\theta$ phase of some $\mathrm{PM}$ was 0.50 , then by definition $\mathrm{pH}_{\mathrm{eff}}^{\theta}=8.06$ : the composition of the phase is such that the values of $\left[\mathrm{H}^{+}\right]$and all the activity coefficients give $\alpha_{\mathrm{fb}}=0.5$, the same as for 
dilute water at $20{ }^{\circ} \mathrm{C}$ with $\mathrm{pH}=8.06$. As suggested above, if $\mathrm{w}, \alpha$, and $\beta$ phases are all present, then differences in the activity coefficient values will certainly cause the three $\mathrm{pH}_{\text {eff }}$ values to be different:

$$
\mathrm{pH}_{\mathrm{eff}}^{\mathrm{w}} \neq \mathrm{pH}_{\mathrm{eff}}^{\alpha} \neq \mathrm{pH}_{\mathrm{eff}}^{\beta} \neq \mathrm{pH}_{\mathrm{eff}}^{\mathrm{w}} \quad \alpha_{\mathrm{fb}}^{\mathrm{w}} \neq \alpha_{\mathrm{fb}}^{\alpha} \neq \alpha_{\mathrm{fb}}^{\beta} \neq \alpha_{\mathrm{fb}}^{\mathrm{w}}
$$

\section{Summary}

The Am form of a low MW amine will in general have reasonable affinities for both $\alpha$ and $\beta$ type phases, so consideration of Eq.(22) indicates that $K_{\mathrm{p}, \mathrm{fb}}^{\mathrm{w}}, K_{\mathrm{p}, \mathrm{fb}}^{\alpha}$, and $K_{\mathrm{p}, \mathrm{fb}}^{\beta}$ will all be roughly similar in magnitude: for all three phase types, the $\zeta_{\mathrm{Am}}^{\theta}$ values will generally be similar, as will the $\overline{\mathrm{MW}}^{\theta}$ values (though $\overline{\mathrm{MW}}^{\mathrm{w}}$ will be smaller than $\overline{\mathrm{MW}}^{\alpha}$ and $\overline{\mathrm{MW}}^{\beta}$ ). And, with significant water uptake into an $\alpha$ phase certain to occur at moderate to high RH values, good solvation of ions will often be possible in an $\alpha$ phase. This will assist protonation of $\mathrm{Am}$ to $\mathrm{AmH}^{+}$in such a phase (as is known to occur for nicotine in tobacco smoke PM). The overall result is that to a first approximation, $\alpha_{\mathrm{fb}}^{\mathrm{w}}$ and $\alpha_{\mathrm{fb}}^{\alpha}$ can be similar in magnitude, making $K_{\mathrm{p}, \mathrm{fb}}^{\alpha} / \alpha_{\mathrm{fb}}^{\alpha}$ likely to be generally comparable to $K_{\mathrm{p}, \mathrm{fb}}^{\mathrm{w}} / \alpha_{\mathrm{fb}}^{\mathrm{w}}$. In a $\beta$ phase, ion solvation will not be as good, so that for acidic aerosol $\alpha_{\mathrm{fb}}^{\beta}$ will generally be closer to one than the other two $\alpha_{\mathrm{fb}}$ values, making $K_{\mathrm{p}, \mathrm{fb}}^{\beta} / \alpha_{\mathrm{fb}}^{\beta}$ smaller than both $K_{\mathrm{p}, \mathrm{bb}}^{\mathrm{w}} / \alpha_{\mathrm{fb}}^{\mathrm{w}}$ and $K_{\mathrm{p}, \mathrm{fb}}^{\alpha} / \alpha_{\mathrm{fb}}^{\alpha}$. Overall, modeling of amine behavior in the atmosphere should include consideration of partitioning organic PM. Unfortunately, this will be more difficult than waterphase only modeling because prediction of $\alpha_{\mathrm{fb}}$ values in multiphase PM will be greatly complicated by the needs to: 1) have estimated values of acidity constants in mostly organic phases of variable composition; and 2) allow distribution of chemicals over multiple liquid phases. 


\section{Acknowledgment}

The authors is thankful for financial support from the Electric Power Research Institute.

\section{References}

Barsanti, K., McMurry, P., Smith, J. 2009. The potential contribution of organic salts to new particle formation. Atmospheric Chemistry and Physics 8, 2949-2957.

Bzdek, B. R., Ridge, D. P., Johnston, M. V. 2011a. Amine reactivity with charged sulfuric acid clusters. Atmospheric Chemistry and Physics 11, 8735-8743.

Bzdek, B.R., Zordan, C.A., Luther, G.W., Johnston, M.V. 2011b. Nanoparticle chemical composition during new particle formation. Aerosol Science and Technology 45, 1041-1048

Bzdek, B.R., Lawler, M.J., Horan, A.J., Pennington, M.R., DePalma, J.W., Zhao, J., Smith, J.N., Johnston, M.V. 2014. Molecular constraints on particle growth during new particle formation. Geophysical Research Letters 41, 6045-6054.

Chan, L.P., Chan, C.K. 2013. Role of the aerosol phase state in ammonia/amines exchange reactions. Environmental Science \& Technology 47, 5755-5762.

Erdakos, G.B., Pankow, J.F. (2004) Gas/particle partitioning of neutral and ionizing compounds to single and multi-phase aerosol particles. 2. Phase separation in liquid particulate matter containing both polar and low-polarity organic compounds. Atmospheric Environment 38, 1005-1013.

Fredenslund, A., Gmehling, J., Rasmussen, P., 1977. Vapor-Liquid Equilibria Using UNIFAC: A Group Contribution Method. Elsevier, Amsterdam, 380 pp.

Ge, G., Wexler, A.S., Clegg, S.L. 2011. Atmospheric amines - Part II. Thermodynamic properties and gas/particle partitioning. Atmospheric Environment 45, 561-577. 
Gonzalez, E., Monge, C., and Whittembury, J. 1980. Ionization constants of 5,5'-dimethyl-2,4oxazolidinedione (DMO) and nicotine at temperatures and $\mathrm{NaCl}$ concentrations of biological interest. Acta Cientifica Venezolana 31, 128-130.

Guo, H., Xu, L., Bougiatioti, A., Cerully, K.M., Capps, S.L., Hite, J.R., Carlton, A.G., Lee, S.-H., Bergin, M.H., Ng, N.L., Nenes, A., Weber, R.J., 2014. Particle water and pH in the southeastern United States. Atmospheric Chemistry and Physics Discussion 14, 27143 27193.

Jathar, S.H., Mahmud, A., Barsanti, K.C., Asher, W.E., Pankow, J.F., Kleeman, M.J. (2015) Water uptake and its influence on gas/particle partitioning of secondary organic aerosol in the United States. Submitted to Atmospheric Environment.

Liang, C., Pankow, J.F. (1996) Gas/particle partitioning of organic compounds to environmental tobacco smoke: partition coefficient measurements by desorption and comparison to urban particulate material. Environmental Science \& Technology 30, 2800-2805.

Pankow, J.F. 1994 An absorption model of gas/particle partitioning in the atmosphere. Atmospheric Environment, 28, 185-188.

Pankow, J.F., Mader, B.T., Isabelle, L.M., Luo, W., Pavlick, A., Liang, C. 1997. Conversion of nicotine in tobacco smoke to its volatile and available free-base form through the action of gaseous ammonia. Environmental Science \& Technology 31, 2428-2433. See also Errata, Environmental Science \& Technology 33, 1320.

Pankow, J.F. 2001. A consideration of the role of gas/particle partitioning in the deposition of nicotine and other tobacco smoke compounds in the respiratory tract. Chemical Research in Toxicology 14, 1465-1481. 
Pankow, J.F., Tavakoli, A.D., Luo, W., Isabelle, L.M. (2003) percent free-base nicotine in the tobacco smoke particulate matter of selected commercial and reference cigarettes. Chemical Research in Toxicology 16, 1014-1018.

Pankow, J.F., Marks, M.C., Barsanti, K.C., Mahmud, A., Asher, W.E., Li, J., Ying, Q., Jathar, S.H., Kleeman, M.J. 2015, Molecular view modeling of atmospheric organic particulate matter: Incorporating molecular structure and co-condensation of water. Submitted to Atmospheric Environment.

Reynolds, A.J., Verheyen, T.V., Adeloju, S.B., Meuleman, E., Feron, F. 2012. Towards commercial scale postcombustion capture of $\mathrm{CO}_{2}$ with monoethanolamine solvent: key considerations for solvent management and environmental impacts. Environmental Science \& Technology 46, 3643-3654.

Rochelle, G.T. 2009. Amine scrubbing for $\mathrm{CO}_{2}$ capture. Science 325, 1652-1654.

Smith, N.O. 1992. Thermodynamics of ionic solid solutions. A new treatment of existing distribution data. Journal of Solution Chemistry, 1992, 21, 1051-1068.

Smith, J. N., Barsanti, K. C., Friedli, H. R., Ehn, M., Kulmala, M., Collins, D. R., Scheckman, J. H., Williams, B. J., McMurry, P. H. 2010. Observations of aminium salts in atmospheric nanoparticles and possible climatic implications. Proceedings of the National Academy of Sciences 107, 6634-6639.

Yli-Juuti, T., Barsanti, K., Ruiz, L., Kulmala, M., Riipinen, I. 2013. Model for acid-base chemistry in nanoparticle growth. Atmospheric Chemistry and Physics, 2013, 13: 12507-12524.

Zheng, J., Ma, Y., Chen, M., Zhang, Q., Wang, L., Khalizov, A.F., Yao, L., Wang, Z., Wang, X., Chen, L. 2015. Measurement of atmospheric amines and ammonia using the high resolution time-of-flight chemical ionization mass spectrometry. Atmospheric Environment 102, 249259. 
343 Zuend, A., Seinfeld, J.H., 2012. Modeling the gas-particle partitioning of secondary organic aerosol: the importance of liquid-liquid phase separation. Atmospheric Chemistry and Physics 12, 3857-3882.

346 


\begin{tabular}{|c|c|}
\hline \multicolumn{2}{|c|}{$\begin{array}{l}\text { Table } 1 \text {. Possible phase combinations involving } \\
\text { four phase types: } \\
\alpha \text { somewhat polar liquid, mostly organic by } \\
\text { mass; } \\
\beta \text { non polar liquid, mostly organic by mass; } \\
\text { w mostly water phase by mass, presence } \\
\text { favored by high RH conditions; and } \\
\text { s solid salt, presence favored by low RH } \\
\text { conditions. }\end{array}$} \\
\hline phase(s) & dominant component(s) \\
\hline$\alpha$ & SOA \\
\hline$\beta$ & POA \\
\hline w & water \\
\hline s & solid salt \\
\hline$\alpha, w$ & SOA, water \\
\hline$\beta, w$ & POA, water \\
\hline$\alpha, s$ & SOA, solid salt \\
\hline$\beta, s$ & POA, solid salt \\
\hline$\alpha, w, s$ & SOA, water, solid salt \\
\hline$\beta, w, s$ & POA, water, solid salt \\
\hline$\alpha, \beta$ & SOA, POA \\
\hline$\alpha, \beta, w$ & SOA, POA, water \\
\hline$\alpha, \beta, s$ & SOA, POA, solid salt \\
\hline$\alpha, \beta, w, s$ & SOA, POA, water, solid salt (Fig.1) \\
\hline
\end{tabular}


Figure 1. Schematic diagram of multiple-phase particulate matter with three liquid phases and one solid salt phase that is a dilute solid solution of an aminium bisulfate in ammonium bisulfate.

\section{four phase PM case:}

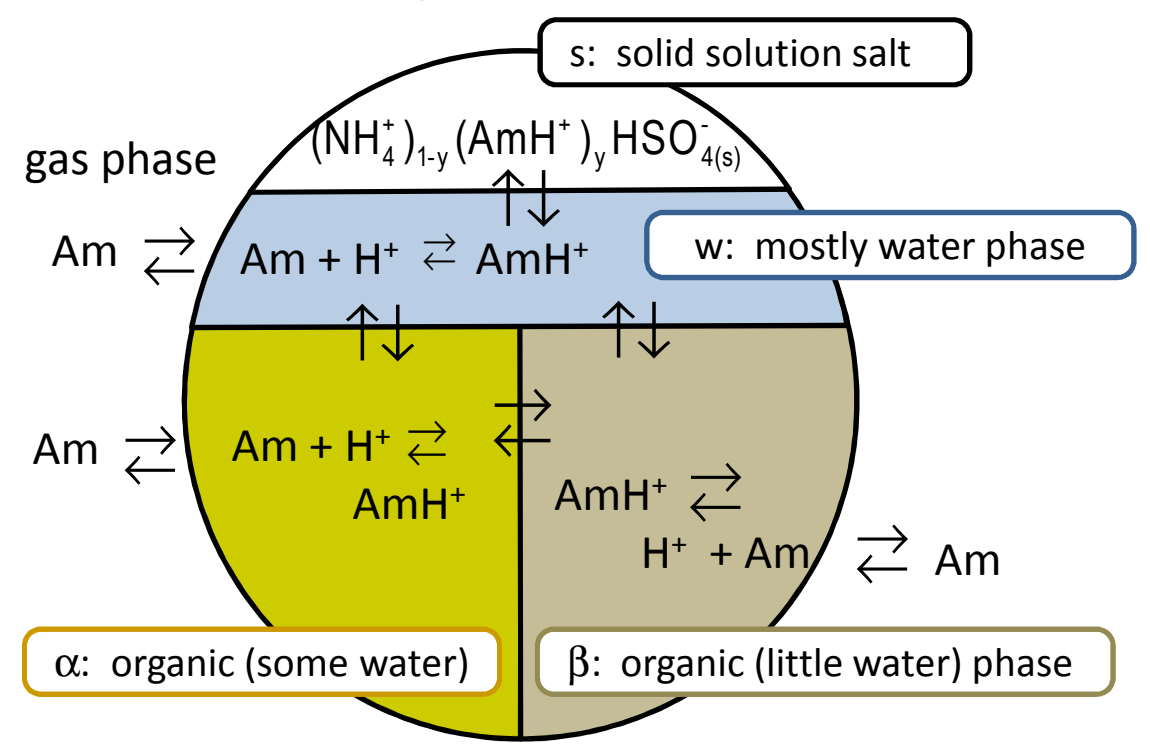




\section{HIGHLIGHTS}

- Amines in the atmosphere can be found in different phases in atmospheric particulate matter (PM).

- Phase of interest include liquid water, organic PM, and solid salt solutions.

- Protonation of an amine $\mathrm{Am}$ to form $\mathrm{AmH}^{+}$can greatly increase partitioning to water and OPM phases. 